\title{
CROQUI, PLISSADO DE PAPEL
} Croqui, ruffle paper

LEE , Erika Yamamoto I Mestre em Artes Visuais

Universidade Estadual de Santa Catarina - UDESC erikaylee@gmail.com

\begin{abstract}
Resumo
A Moda da atualidade se aproxima da arte e do pensamento para manifestar conceitos críticos através de espetáculos em passarelas no qual provoca e perplexa o público deixando rastros de reflexão. Este texto tem a finalidade de contaminar o conceito deleuziano nos processos criativos do "ser criador" seja ele artista ou designer de moda. Os trabalhos do estilista Jum Nakao permeiam no espaço da teoria crítica, a potência de seus trabalhos disseminam a multiplicidade das possíveis combinações para pensar o retorno, o novo. O método que Nakao propõe na construção da moda atual contamina pela descostura do objeto (roupa) para se refletir nas partes (moldes) vivenciando a ausência da totalidade, e forçar o encontro noutras conexões possíveis ao invés de sempre repetir os mesmos moldes costurados no corpo. Tal apropriação das técnicas artísticas contemporâneas, Nakao engrandece teoricamente, bem

\section{Abstract}

The Fashion of the current approaches of art and thought to express critical concepts through spectacles on catwalks in which causes the audience puzzled and leaving traces of reflection. This text aims to contaminate the Deleuzian concept in the creative processes of "creative being" whether artist or fashion designer. The work of artist and designer Jum Nakao permeate the space of critical theory, the power of his works spread the multiplicity of possible combinations to think about the return, the new. The method proposes to build Nakao current fashion contaminated by mis-seaming the object (clothes) to reflect the parties (molds) experiencing the absence of totality, and force against other possible connections instead of always repeating the same patterns sewn into the body. Such appropriation of contemporary artistic techniques, Nakao magnifies theoretically as well as your name and brand in the fashion market.
\end{abstract} como, seu nome e marca no mercado de moda.

Palavras Chave: Comunicação de marketing. Marcas de moda. Percepção dos consumidores. Propaganda impressa.

Keywords: Marketing communication. Fashion brands. Consumer perceptions. Print ads. 


\section{INTRODUC̣ÃO}

\section{Moda Contemporanea, Criação e Jum Nakao}

Para compreender o contexto pelo qual Jum Nakao atua na moda, vejamos um breve histórico do processo que tais lançamentos e novidades vem se desencadeando. A moda do século XXI aposta na construção de uma fantasia e promessa de satisfação, sensação e beleza. Desde a Revolução Industrial o belo tornou-se novidade e o feio, o ultrapassado. O hábito de mostrar a nova coleção de um determinado costureiro surgiu em 1900, numa teatralização do mercado em torno da imagem, desejo e relações pessoais. A história registra que os desfiles começaram para a finalidade em expor a roupa criada pelo estilista, destacando as manequins que a vestiam por sua altura, postura e elegância do caminhar (EVANS, 2002). A apresentação ocorria em salões e clubes da alta sociedade, que, com o tempo, passaram a ocupar um espaço maior pela quantidade de pessoas que vinham apreciar. Assim, foi sendo construído esse espaço da criação do desejo, em relação às roupas, ao corpo de beleza padrão (de manequim, top model) e ao espaço de sonho e teatralidade. Um contexto inscrito num símbolo de prestígio, luxo, poder e fantasias.

O espetáculo da moda contemporânea impõe uma movimentada e intensa rotação de novas coleções, um novo show de promessa a cada temporada, duas a três de inverno e outras duas a três de verão, quatro a seis ao ano. A moda encontra certa erudição e visibilidade na arte, um outro status dado ao objeto roupa enquanto construção da imagem, mas também como produto e marca. Recorre-se a uma apropriação de pensamentos artísticos, como as performances e as instalações, linguagens e técnicas aplicadas pelo estilista Jum Nakao. Essa espetacularização toca na satisfação de necessidades e implica no complexo mercado capitalista de moda. A aproximação de conceitos, de certas noções de beleza e sofisticação, estimula pesquisas em torno de experimentos que resultam em concepções que indicam questões como a multiplicidade do indivíduo.

O Nakao é um desses envolvidos com o mundo da moda e seu mercado, que procura criar conceitos por meio da desconstrução da roupa, ao mesmo tempo questiona o sistema moda e o imperativo mercadológico na busca de um grupo seleto de consumidores dessa própria moda. Com pensamentos artísticos e teoria crítica, contamina e dissemina problemas entre a criação e a limitação regida pela política comercial. A moda performática de bloco de ações do Nakao, obriga novas leituras sobre arte e moda. Neste breve texto, vamos nos limitar à dois trabalhos para problematizar a questão. Desde seu desfile "A costura do invisível" (SPFW 2004), repetiu sua boneca playmobil na instalação "Revolver" (MON, 2007) e vem se envolvendo com trabalhos de 
mesma concepção, ou seja, moda manifesto entre os espaços da arte e da moda solicitando um olhar mais profundo para o campo da criação. Na área da moda, expõe um corpo limpo, depurado, modelo de perfeição, estes trabalhos tendem a responder com um corpo que se encontra no limiar entre o homem e o animal, questiona as necessidades que o homem concebe como sobrevivência, fantasia e desejo por meio da desterritorialização, reterritorializa no território da criação.

Jum Nakao iniciou suas experimentações na moda desde o início da década de 90, mas foi com o desfile "A costura do invisível" de 2004 que se consagrou na moda brasileira e internacional, um universo que tem acrescido um olhar teórico e reflexivo com relação às ações ritualísticas também visíveis em desfiles e lançamentos. O estilista, formado em artes plásticas, há 27 anos desenvolve e explora a moda através do pensamento artístico e da construção de seu nome artístico-mercadológico. Neto de japoneses, ele nasceu em 22 de outubro de 1966, no interior paulista. Recebeu uma educação conforme tradição nipônica, através de princípios, costumes e sensibilidade pela arte japonesa, uma cultura que mantém uma relação intensa com o silêncio, o vazio, a percepção do tempo e abrangência sensorial distintas. (NAKAO, 2009).

Em entrevista, o estilista afirma que a moda é algo que o aproxima das pessoas (NAKAO, 2009). Ele também busca promessa de beleza e sofisticação, ornamento e leveza, e, ao mesmo tempo, faz um questionamento sobre tudo que ela promete comercializar ou acessar. Um estilista flanêur que habitualmente pedala pelas ruas de São Paulo, pelos parques, deseja o contato com as pessoas, não para conversar, mas para observar seus gestos e costumes. Empreende o hábito do ser criador, do artista, do escritor que está sempre à espreita, atento ao que circunda seu devir-território. Assim, embaralhando os circuitos, ele cria um paradoxo que, dependendo do conceito da coleção, não é direcionado mercadologicamente, embora se torne surpreendente como arte. Com isso, leva a pensar os diferentes aspectos que esse fenômeno pode alcançar, coloca em xeque a noção de moda como consumo, num território no qual as relações entre moda e arte são inconstantes e incomuns.

\section{Moda Contemporânea: Contexto}

A apropriação das performances e instalações que os estilistas internacionais assumem no século $X X I$ repercutem no pensamento de Jum Nakao, que trabalha e sugere pela descostura da roupa. Ele expõe o problema entre o território da criação que se encontra em choque com o imperativo sistema, regido por regras, leis tramadas pelo poder mercadológico e limitadoras das infinitas combinações que esse campo pode alcançar. 
O sistema da moda é uma legitimação social de formas, cores, dimensões e configurações plásticas do vestuário à extensão do corpo, objetos que o protegem e o cercam. $O$ design de moda classifica esses objetos em cinco camadas de pele: a primeira, a epiderme; a segunda, a roupa; a terceira, a casa ou o automóvel; a quarta, o meio social; e, a quinta, a humanidade e o meio ambiente. São peles, tais como conhecidas pela metodologia de Friedensreich Hundertwasser (1928-2000), mas também uma das atividades projetuais do design que requer planejamento do objeto em função do corpo humano (MARTINS, 2008).

O foco desta pesquisa se dirige ao contexto social da moda para pensar a moda-arte visual, numa leitura conceitual das obras de Jum Nakao que contextualizam a moda-criação. Este ato de extensão da roupa para o objeto de arte, respeita o rigor estético para o objeto "roupa" e seu cenário, a moda-criação passa para o estado de fruição conferindo importância ao pensamento artístico seguido da precisão teórica. Estilistas estudam as artes contemporâneas e nelas mergulham para obter objetos prolíferos na construção de blocos artísticos, donde proferem em paralelo seus nomes e marcas.

Este jogo de publicidade funciona bem com as ações e performances dos designers frente ao campo de visão do público alvo (espectador) levando em conta o rigor técnico e teórico dos processos criativos resultando o objeto (coleção de roupas, ação, cenário) novo, complexo no entendimento comum, este objeto perturba a historicidade da percepção comum, global. Tal "estranhamento" do espectador torna o objeto potente, latente na memória das pessoas, porque o artista/designer inova na raiz, na parte do seu ideal interno e encarna, materializa neste novo objeto.

A história da vestimenta assume importância no período monárquico europeu, com sua suntuosidade extravagante, teatralização desde a roupa até a decoração e a pintura. A vestimenta fascina artistas e intelectuais pela adoração e admiração ao luxo e a opulência. Com a alta costura, o costureiro surge como nova casta de criador tornando-se o ditador da moda na qual atribui o topo de uma imagem ideal. (LAVER, 2005). Nas inspirações criativas e na busca da perfeição, os costureiros se igualam aos artistas de sua época, formando a autonomia, o essencialismo da perfeição. Na verdade, a reciprocidade entre moda e arte vem de muito tempo, em obras documentadas pelas pinturas renascentistas de Jan van Eick (1390-1441), Ticiano (1473-1490), Sandro Boticelli (1455-1510), bem como os esboços de vestidos do figurinista milanês Giuseppe Arcimboldo (1527-1593). Vestidos artísticos de Henry van de Velde (1863-1957) e Gustav Klimt (1862-1918) se filiavam a movimentos artísticos que mostravam mudanças com o domínio das máquinas e formas abstratas entre o arts \& crafts e o art nouveau. Assim, na história social, a roupa e o 
sistema de moda foram se espiralando entre as formas, as significações dentro de seu tempo, sem deixar de buscar a estética da beleza. Consideremos, a seguir, alguns conceitos de moda fruição na contemporaneidade.

No conceito de moda de Georg Simmel (1858-1918), o homem é um ser dualista e possuidor de unidade plurívoca de multiplicidades que se exteriorizam por intermináveis fragmentos, cujas possibilidades permitem sentir suas forças e tensões profundamente. O primeiro sinal é o espírito que pede por uma tendência geral e, em acréscimo, para captar a individualidade. Observa-se que a

[...] oscilação da nossa alma entre estes dois pólos se possa materializar no antagonismo da doutrina da unidade do todo e do dogma da incomparabilidade, do ser-para-si de cada elemento do mundo, embora eles se digladiem praticamente como opostos partidários do socialismo e do individualismo, é sempre uma só e a mesma forma fundamental da dualidade que, por fim, se revela na imagem biológica como o antagonismo entre hereditariedade e variabilidade - a primeira como portadora do geral, da unidade, da igualdade consolidada de formas e conteúdos da vida, a outra como mobilidade, a multiplicidade de elementos particulares, o desdobramento inquieto de um conteúdo de vida individual que gera outro (SIMMEL, 2008, p. 22).

A imitação parte dessa transmissão, um impulso enquanto princípio que caracteriza um estado de evolução. O consumo dos produtos de moda forma um círculo social que isola simultaneamente os outros. Simmel (2008) compara a moda com a moldura de um quadro que possui universo de todo unitário, concentrado, e que atua ao mesmo tempo para o exterior, de sorte que o indivíduo se preserva no círculo social de seu território. Desde um século atrás, essa relação arte e moda influencia a geração construtiva de sensação e sinestesia cruciais para as demandas atuais.

A moda, como construção dessa dinâmica à procura da própria essência, emerge no final do século XX e se estende até o século XXI. De acordo com Sant'Anna (2009), pauta-se no conceito de que o cidadão moderno abandona todas as crenças religiosas, ideais revolucionários e políticos, na busca da prática hedonista. A compreensão destas questões sociais resulta num ethos da sociedade moderna e pessoal que articula as relações entre o social, partindo das aparências e estabelecendo o novo como categoria hierarquizadora de significados. Tal hierarquização se constrói nos significados para a articulação 
do aparecer e ser visto.

Para Sant'Anna (2009), a moda contemporânea é a expansão do sistema de moda para além dos grupos mais ricos, é mundial, simultânea em busca do belo, novo, sensacional. Nessa lógica do ethos, o campo midiático atualiza a forma-moda, legitima as necessidades imediatas através da construção da marca, seja pela apropriação da teatralidade, performance ou instalação. O campo da moda proporciona fantasia de possuir o novo, ou seja, mergulha em algo que tem a função de tocar o imaginário e mexer no turbilhão da máquinadesejante'.

A forma-moda também, e maciçamente, encontra-se expressada em todo o sistema cultural, no qual os bens simbólicos são composições de artifícios de encontro de si, no consumo de um modelo para todos. Da indústria fonográfica à publicação literária é provocada uma renovação acelerada e uma diversificação estratégica, não apenas para vender mais, mas, principalmente, para se revestir de uma conotação positivada de erudição (SANT'ANNA, 2009, p. 93).

Nessa clave da erudição, busca-se a teoria das artes visuais. Na fronteira entre a arte e a moda cabe introduzir o termo artisticidade pelo qual Cidreira (2009) coloca em questão a simultânea definição de que moda e arte podem ser trabalhadas como construção, conhecimento. Aqui, no âmbito de construir uma imagem marcante, durável na memória do espectador, como a arte permite eternizar, o que contribui simultaneamente à construção de seu nome e marca publicitária, no qual, discutiremos a apropriação à seguir.

A arte constrói sensação em performances e instalações, pois nesse bloco se pode exteriorizar o pensamento do artista, a erudição teórica, o abandono da expressão como mera manifestação da subjetividade. Confere, também, visibilidade do objeto único como múltiplas possibilidades, uma obra viva em incessante devir. Reconfigurada, a concepção de arte, que se constitui por ações de forças e de certos contornos que cristalizam a ação criativa, abre um grande leque. Vários conceitos pós-modernos levam à reflexão do pensamento filosófico contemporâneo, de modo a fazer incidir na ação teórica e prática da moda contemporânea.

A moda contemporânea circunscreve o corpo num corpo da mídia, do espetáculo, que desvia a vida sentimental para a sensorial. A posse e o manuseio

$1 \quad$ O termo máquina-desejante foi retirado do estudo de Deleuze sobre o sistema de cortes-fluxo na produção do desejo. 
do objeto representam um alvo de "felicidade", o que provoca uma corrida coletiva incessante em busca desse bem-estar. E, na experiência estética, temse uma ligação direta à percepção que reconhece os valores pelo senso de apreensão dos objetos.

A experiência estética é constituída por três categorias essenciais, segundo Jauss (1979 apud LEE, 2012): a poiesis, como ato da criação pensada pelo artista/ estilista com interação prazerosa; a aisthesis, que designa o prazer estético da percepção e reconhecimento como receptor que contempla as realidades interna e externa; e a kátharsis, que finaliza a experiência, multiplicando-a por meio da identificação entre o objeto e o sujeito fabricado na poiesis e na aisthesis O resultado é a incorporação da obra numa apreciação reconfigurada. Esse prazer renovado está impregnado e legitimado na apreciação do ver (imagem) e de ser visto (vestir/moda) (JAUSS, 1979 apud SANT'ANNA, 2009). Tais objetos estão no universo físico que facultam o espectador a superestimar essa sensação de gozo prolongado, materializado em seu corpo.

$\mathrm{Na}$ construção do desejo desses objetos sensoriais, a estratégia mercadológica das marcas passou a incorporar as artes visuais, criando desfiles performáticos e instalações que convergem no produto-objeto e na imagem conotativa da distinção social, que se esvaiu para além da compreensão de Simmel (2008). A propósito dessa ideia de moda-instalação, pela interação com o corpo, que é um dos suportes do campo moda, Villaça (2011) também pensa a moda do século XXI nessa clave, a do cruzamento com as artes, num viés mercadológico, com fins de construção da marca, do nome do estilista:

\begin{abstract}
O que queremos sublinhar nos anos 2000 é a ampliação desta narrativa de apropriação da moda que se desloca incessantemente abarcando de forma criativa espaços reais, recursos tecnológicos, com uma especial identificação com o mundo da arte, enfatizando novos processos de subjetivação e ambientação do sujeito contemporâneo com sutis estratégias de envolvimento, nos quais o fortalecimento das marcas é o que mais importa quando se pensa no licenciamento de uma infinidade de produtos. É a moda que estamos chamando de instalação. (VILLAÇA, 2011, p. 219-220).
\end{abstract}

A distância entre moda-instalação e moda-performance é um espaço indecidível. Villaça (2011) questiona essa relação homem e matéria no universo contemporâneo e o consumo dos bens simbólicos e imateriais, quando o cidadão se deixa apaixonar e se tornar um produto tecnológico ou um novo 
programa virtual, um objeto de alto valor agregado. A contextualização parte do social, sensorial (experiência estética, fruição) para aproximar o espaço da arte e da moda, retirar a subjetividade e deslocar o olhar para o universo artístico que se direciona a outras leituras e reflexões contemporâneas.

Nessas indagações artísticas reside a artisticidade, visível no trabalho dos estilistas, a fim de criar a imagem potente entre a ideia e as cinco peles do design já referidas. A teoria de arte e imagem circunda o campo da estética, reforça uma reflexão sobre a origem e a subjetividade contemporânea entre a sinestesia de construção do objeto no desejo-conjunto, devir-desejo, deviranimal, do que circunda os trabalhos de Jum Nakao.

\section{Arte Performática}

A performática "Costura do invisível" de Nakao, nos força a buscar quais os métodos que uma performance atinge o público. Pensando na performatividade e nos espetáculos dos desfiles, a arte do vestir e o consumo ganharam novos sentidos com a proliferação da pop art, que fez crítica à sociedade de consumo, e da estética kitsch. No frenesi dessas apresentações, a performance faz parte da história de um meio de reflexão flexível e ilimitado, com inúmeras variáveis, geralmente praticado por artistas dinâmicos e impacientes que propõem uma arte direta com o público. Qualquer definição precisa negaria o propósito da prática, pois segue uma liberdade disciplinar entre pintura, poesia, literatura, dança, música ((Erik Satie (1866-1925), John Cage (1912-1992)), arquitetura, vídeo, cinema e narrações, empregando infinitas combinações, o que proporciona a cada performer criar sua própria regra, ao longo da execução e dos processos. Essa arte provém de limitações na atuação do meio artístico, como nos museus e galerias. A curadora e pesquisadora Roselee Goldberg salienta:

\begin{abstract}
[...] como a presença viva do artista e o enfoque em seu corpo se tornaram cruciais para as concepções acerca do "real", além de constituírem uma base para o desenvolvimento das instalações, da videoarte e da fotografia de arte [...] $\mathrm{O}$ que se pretende mostrar é antes o desenvolvimento de uma sensibilidade. (GOLDBERG, 2006 apud LEE, 2012, p. 30).
\end{abstract}

Aliberdade de se exprimir pelo próprio corpo, em linguagem multidisciplinar, veio da herança dos manifestos futurista, construtivista russo, até o dadaísmo e o surrealismo. O movimento futurista teve a característica marcante de atacar os valores estabelecidos da pintura e das academias literárias, criando

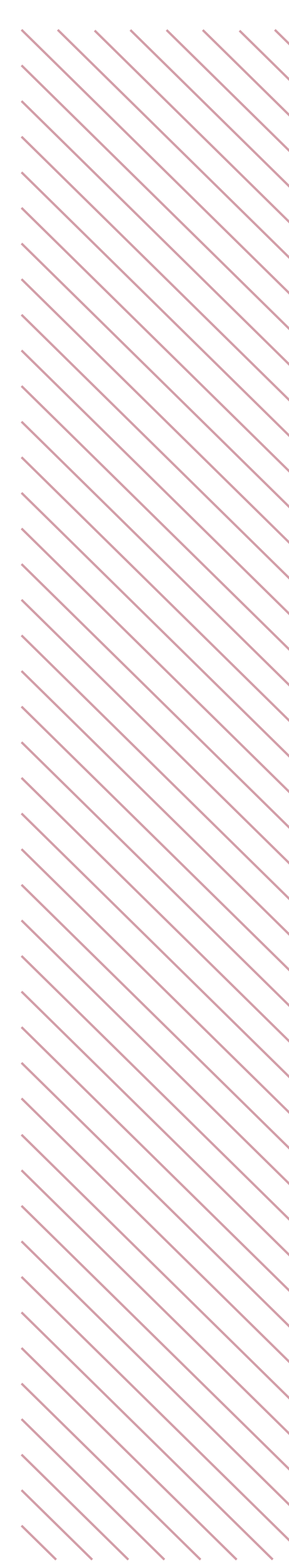


excêntricos e ruidosos versos livres em sátiras, ações repugnantes e até sórdidas. O precursor Filippo Tommaso Marinetti (1876-1944) escolheu o público parisiense para começar esses manifestos. Assim, como os pintores Yves Klein (1928-1962) e Jackson Pollock (1912-1956), e literatos, como James Joyce (1882-1941) se transformaram em performers, apresentaram suas obras em saraus, caricaturas, ruídos e movimentos mecânicos, teatro de surpresa, práticas disseminadas pela França, Itália, Rússia, entre outros países, nas décadas de 1910 a 1930. A performance busca outras formas de exprimir o pensamento contemporâneo, liga-se ontologicamente a uma "arte da vida", algo vivo que anula uma posição sacramentada e elitizada em espaços "mortos" de museus e galerias. A arte passava por um processo de entropização e liberdade automática, no período entre Guerras (COHEN, 2011). Nessa época, a moda ganhava amplitude e público, com Charles Worth (1825-1895) e Paul Poiret (1879-1944), que criaram o hábito de exibir suas criações em manequins vivas, postulando a tradição de mostrar as novidades em eventos sociais de prestígio, assim como as estilistas Coco Chanel (1883-1971) e Elsa Schiaparelli (18901973).

\section{Apropriação da Arte Performática para a construção do nome e da marca de Moda}

Artistas e estilistas vêm se entusiasmando com as produções desses Acontecimentos ou seja, Acontecimento numa imagem transcendental, desvinculado de mais um evento, e sim, um bloco construído de pensamento (pintura, escultura, performance) no qual transcende como lembrança em infinitas combinações que retornam diferentes. Desde o começo dos desfiles, no início do século $X X$, a tradição ocidental de arte, constrói um bloco de sensibilidade, conhecimento e expressão. A arte é sempre uma construção, de modo que, nesse espaço da moda se apropria da arte para a criação e erudição da moda-espetáculo. Mais do que circunscrever o corpo e ampliá-lo, prolifera além das suas camadas descritas no design.

Os desfiles de moda-espetáculo e seus respectivos criadores, os estilistas, dividem-se em cinco categorias de desfiles-performances, segundo Duggan (2002): espetáculo, substância, ciência, estrutura e afirmação. O primeiro se configura na grande produção sonora, luzes, modelos famosas, tema popular e encerramento com custos exorbitantes na finalidade estratégica mercadológica. Nessa categoria está o estilista britânico Alexander McQueen (1969-2010), John Galliano, designers que costumam deixar o público ansioso pelas novidades da coleção. O desfile de McQueen, de 1999, o Savage Beauty, no espaçodomuseumetropolitano, em Nova York se destacou com uma manequim sobre 
uma superfície giratória e robôs mecânicos atirando tintas amarelas e pretas, simulando os gestos de Pollock (conversa entre pintura, performance e moda). Já John Galliano agrega valor à sua marca com vestidos glamorosos, pesados, apresentados em grandes e luxuosas locações.

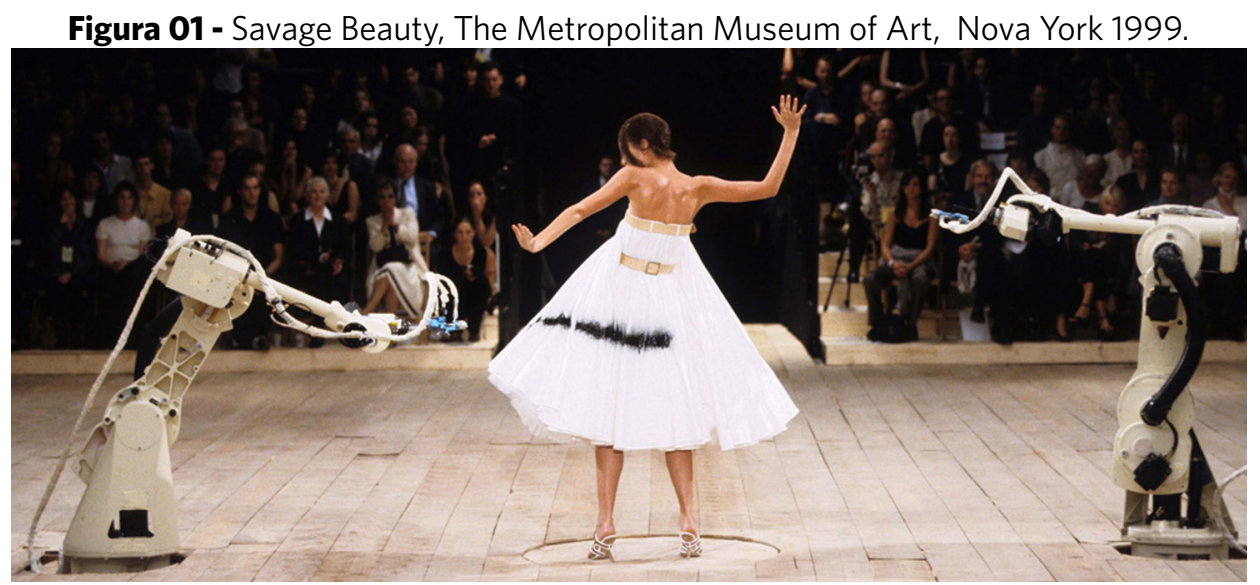

Fonte: Mc Queen (1999).

O desfile substância consiste na performance que destaca o processo e a compreensão conceitual que vai além roupa, abstrai a partir da ideia. Salas vazias com modelos que se vestem no cenário são proposições do designer turco Hussein Chalayan, que deixa a vestimenta em segundo plano ou permite que os vestidos tenham sua forma e molde alterados. Com recursos, como o controle remoto (tecnologia, arquitetura, experiência da matéria e a roupa tecnológica em movimento), afetam espaços conversando entre o interior e exterior do corpo.

Viktor e Rolf (Rolf Snoeren e Viktor Hosting, ambos nascidos na Holanda, em 1969) são conhecidos pelas produções criativas que exploram conceitos mais elaborados de sentidos abstratos em desfiles ritualísticos. Ousados, eles satirizam e ironizam a busca frenética pelo novo do imperativo mercado. Como desprezam o lucro ganham consistência na área acadêmica e na arte (extensão do corpo, da roupa espetáculo, da abstração de modelagens clássicas, desconstrução e reconstrução visual).

O desfile ciência enfatiza a função do tecido e da roupa, no estudo tecnológico dos materiais, não tendo o cenário, o aparato mercadológico como objetivo principal. Estilistas como Junya Watanabe e Issey Miyake seguem esse caminho com os trabalhos performáticos dos artistas, o americano Bruce Nauman e o sul-coreano Nam June Paik (1932-2006), que aproveitam as inovações tecnológicas e fogem da arte tradicional para as experimentações. Metamorfoses das peças de roupas são bem comuns, nesse tipo de design, em que a funcionalidade se expande com a transformação da roupa em sacola ou 
capa. Miyake, o criador do movimento "A piece of cloth", dinâmica e coleção conhecidas como A-POC, sugeriu infinitas possibilidades a partir de um rolo de tecido, cortes, recortes, pontos e linhas animadas por meio de registro em vídeos, exposto de várias maneiras, via desfiles e instalações. A ciência desenvolve a tecnologia do tecido, novos possíveis materiais até combinações de infinitas formas que um molde ou módulo possibilita alcançar.

A categoria estrutura desenvolve roupa como escultura, retira as formas convencionais do corpo, compreende outras possibilidades estéticas e rotula o estilista como vanguardista. A japonesa Rei Kawakubo e o belga Martin Margiela se concentram nessa categoria de estilista-artista. Eles fotografam e performam, manifestando e destacando a questão da forma plástica convencional (imperativo). Seus desfiles não contêm narrativa, nem enredo; muitas vezes, descosturam as roupas em nome da peça artística. A coleção primavera/verão de 1997 de Kawakubo para a casa Comme des Garçons reforça a preocupação com as formas da roupa, distorce o corpo feminino, ao invés de favorecê-lo, como se faz na moda convencional. Margiela contesta a própria criação na moda, com seus formatos achatados carentes de espessura e criatividade na alfaiataria. A roupa ganha "vida" e caimento, movimento preenchido com o suporte do corpo, esticada na superfície lisa, sem "corpo e movimento comum", reflete em outra coisa além. A forma estrutural ultrapassa o funcional, significa criticar o próprio formato estrutural da criação na moda.

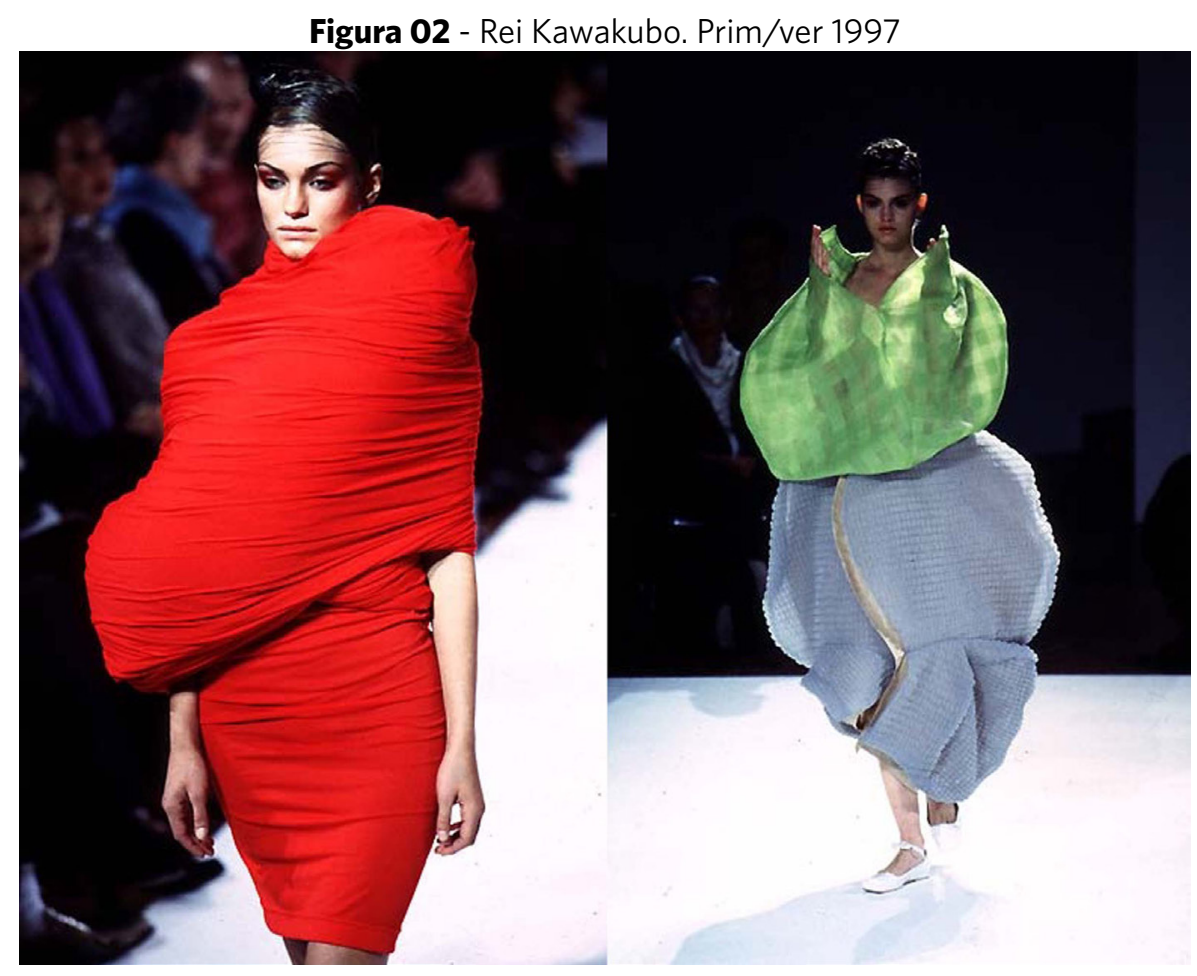

Fonte: Arttatler (1997). 
Desfile afirmação provém da herança performática da década de 1970, num tom crítico e político que lembra mais um manifesto com temas conflitantes. $O$ espanhol Miguel Adrover e a brasileira Karlla Girotto objetivam, na vestimenta, transpassar mensagens contestadoras contra a indústria da moda, contra marcas (vide figura 03) Manifestam-se sobre o absurdo da obcecada busca de fama, status e estimulam a moda alternativa. Porém, discordando da atitude de grifes consagradas, invertendo a exposição da etiqueta, não remetem à construção de sua própria marca? Adrover contesta a obsessão pelas marcas que se fazem valer acima da criação-moda. Na São Paulo Fashion Week, a designer Karlla Girotto fez, em 2007, uma performance ao ar livre, no Pavilhão do Ibirapuera, para apresentar uma coleção de roupas. Manequins masculinos com o padrão de beleza imperativo desciam uma escadaria. No espaço deste cenário flutuavam roupas penduradas em cabides e presas a balões brancos. Ao soltá-los, céu afora, a estilista questiona a supervalorização neste mercado de corpos magros esbeltos. A crítica ao corpo padronizado contém elementos lúdicos, como os balões flutuantes que emitem sensações de sonho, de vôo sem destino certo, um possível convite para se perder ou se encontrar em outro território. Girotto desterritorializa, abandona a passarela, apropria-se de elementos artísticos e faz um desfile contestador de maneira criativa.

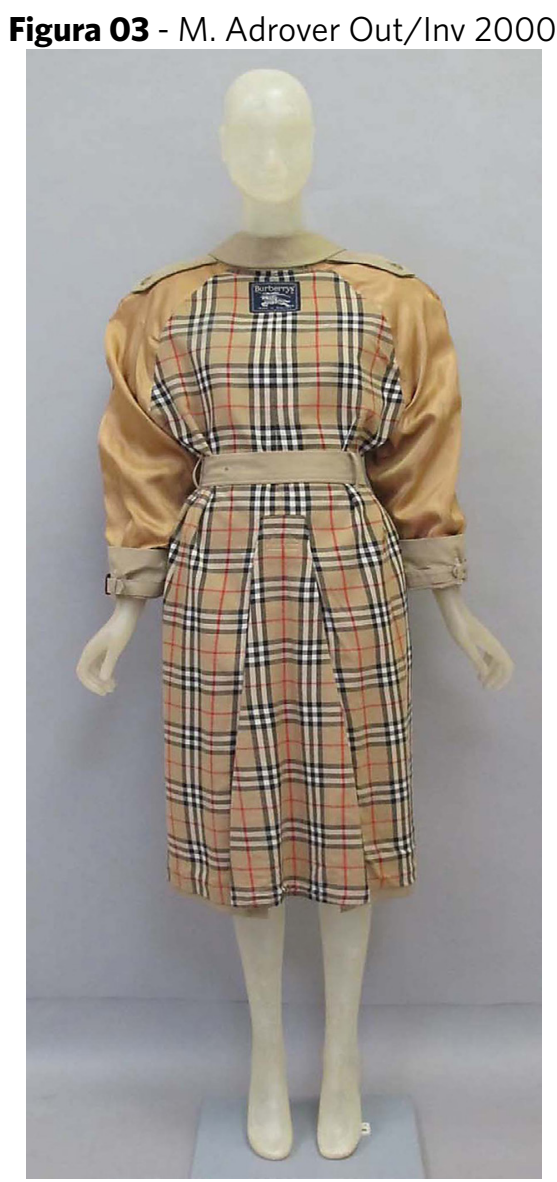

Fonte: Metropolitan Museum (2000). 
Jum Nakao se enquadra em pelo menos três categorias de construção performática na moda: a primeira, de substância, revela-se pelo questionamento sobre a institucionalização da moda, o esmagamento criativo, questiona a atuação do professor em espaço acadêmico visando à descostura de peças e pensamentos prontos demais em favor de um olhar mais amplo à partir das subjetividades criadoras forçando resolver problemas abrindo a esteira das possibilidades que apenas o criador alcança a solução, como o animal encontra para sobreviver. A segunda categoria, a estrutura, quando Nakao transforma jaquetas em mochilas ${ }^{2}$, somatiza a funcionalidade de seu produto, ou seja, de sua marca.

$E$, por último, enquadra-se na categoria afirmação, porque costura roupas em papel vegetal, desfuncionaliza o papel utilitário e rasga, instaura o pensamento de que é uma experiência que cintila, redobra, desdobra num devirenvoltório quase leibniziano ${ }^{3}$. Estas categorias contribuem para distinguir os espetáculos da moda, que se apropriam das práticas das artes contemporâneas, que se convergem ao terreno da criação.

Fechando o raciocínio deste breve texto pode-se concluir que o campo da criação possibilita pensarmos "o corpo" libertá-lo da institucionalização, da historicidade cronológica e do titânico mercado, através da procura do ponto prolífero da percepção interna do ser criador, buscar liberdade confrontando forças de leis e regras impostas (limitante criativo). Mark Zuckerberg ${ }^{4}$ criou o objeto que relaciona o sujeito a partir de uma carência particular, transformandose em um dos maiores inventores do mundo contemporâneo, segundo a Forbes (2013), soube reterritorializar num terreno deserto (universo virtual) compartilhando as sensações do parecer e ser visto, do ser "amado", captando as necessidades de sobrevivência do sujeito de seu tempo e território. O corpo livre cria entre o instinto animal e a satisfação das necessidades buscando criar pelo todo, pelo corpo inteiro sem separar o pensamento cartesiano do sensorial, eis a multiplicidade das possibilidades, um infinito à ser sempre descoberto. Um exercício de descontruir a roupa e compreender o "corpo" como o território infinito de combinações e conexões que a inteligência sincrética de percepção do designer de moda pode recosturar, sempre diferente.

\section{REFERÊNCIAS}

ARTTATLER. Rei Kawakubo. Primavera. 1997. Disponível em: <www.

$2 \quad$ Coleção de Nakao apresentada em 1992.

3 Trata-se do termo que provem de Leibniz, uma ideia que toda novidade se trata de uma seleção em dobra do passado. Corrente no texto de Badiou (1997)

$4 \quad$ O criador da rede social Facebook. 
arttatler.com>. Acesso em: 27 jan. 2012.

BADIOU, Alain. Deleuze, o clamor do ser. Tradução de Lucy Magalhães. Rio de Janeiro: Zahar, 1997.

CIDREIRA, Renata Pitombo. Os sentidos da moda. São Paulo: Annablume, 2009.

COHEN, Renato. Performance como linguagem. 3. ed. São Paulo: Perspectiva, 2011.

DELEUZE, Gilles. Bergsonismo. Tradução de Luiz B. L. Orlandi. Rio de Janeiro: Ed. 34, 2004.

DELEUZE, Gilles. Diferença e repetição. Tradução de Luiz B. L. Orlandi e Roberto Machado. 2. ed. São Paulo: Graal, 2009.

DELEUZE, Gilles; GUATTARI, Félix. Mil platôs, capitalismo e esquizofrênia. Tradução de Aurélio Guerra Neto, Ana Lúcia de Oliveira, Lúcia Cláudia Leão e Suely Rolnik. Rio de Janeiro; Ed. 34. 2008. v. 3.

DELEUZE, Gilles; GUATTARI, Félix. Mil platôs, capitalismo e esquizofrenia. Tradução de Suely Rolnik. Rio de Janeiro: Ed. 34. 2008. v. 4.

DELEUZE, Gilles e GUATTARI, Félix. Mil platôs, capitalismo e esquizofrenia. Tradução de Peter Pál Pelbart e Janice Caiafa. Rio de Janeiro: Ed. 34, 2008. v. 5.

DUGGAN, Ginger Gregg. O maior espetáculo da terra. Revista Fashion Theory, São Paulo, v. 1, n. 2, p. 3-28, jun. 2002.

EVANS, Caroline. O espetáculo encantado. Revista Fashion Theory, São Paulo, v. 1, n. 2, p. 33-66, jun. 2002.

FORBES. The world's bilionaire's. 2013. Disponível em:<http://www. forbes.com/ profile/mark-zuckerberg/>. Acesso em: 20 ago. 2013.

LAVER, James. A roupa e a moda: uma história concisa. São Paulo: Companhia das letras, 2005.

LEE, Erika Yamamoto. Jum Nakao: moda e pensamento artístico. 2012. 115f. Dissertação (Mestrado em Artes Visuais) - Centro de Artes, Universidade do Estado de Santa Catarina, Florianópolis, 2012. 
MARTINS, Suzana Barreto; PIRES, Dorotéia Baduy (Org.). Design de moda olhares diversos. Barueri: Estação das Letras e Cores, 2008.

MCQUEEN, Alexander. Savage beauty: the Metropolitan Museum of Art. Nova York, 1999. Disponível em: <www.alexandermcqueen.com>. Acesso em: 4 mar. 2013.

METROPOLITAN MUSEUM. Miguel Adrover. Outono/Inverno. 2000. Disponível em: <www.metmuseum.org.>. Acesso em: 4 mar. 2013.

NAKAO, Jum. Entrevista concedida a Erika Yamamoto Lee. Curitiba, 9 ago. 2009.

SANT'ANNA, Mara Rúbia. Teoria de moda: sociedade, imagem e consumo. 2. ed. Barueri: Estação das Letras e Cores, 2009.

SIMMEL, Georg. Filosofia da moda. Tradução de Artur Morão. Lisboa: Texto e Grafia, 2008.

VILLAÇA, Nízia. A edição do corpo: tecnociência, artes e moda. 2. ed. São Paulo: Estação das Letras e Cores, 2011. 


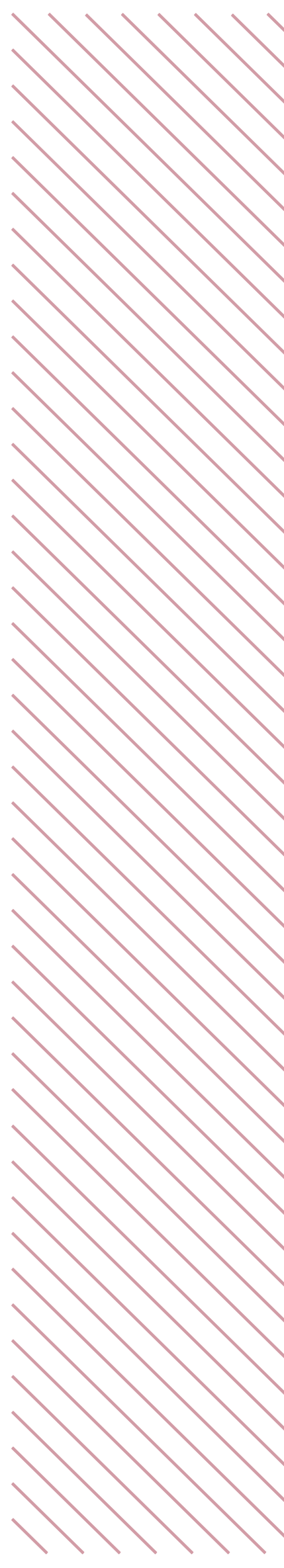

